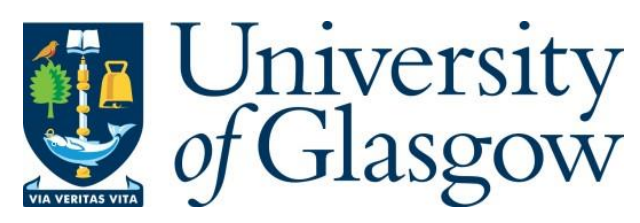

Nikolaou, C. K., Robinson, T. N., Sim, K. A. and Lean, M. E.J. (2020) Turning the tables on obesity: young people, IT and social movements.Nature Reviews Endocrinology, 16(2), pp. 117-122.

There may be differences between this version and the published version. You are advised to consult the publisher's version if you wish to cite from it.

http://eprints.gla.ac.uk/205935/

Deposited on: 1 August 2020

Enlighten - Research publications by members of the University of Glasgow http://eprints.gla.ac.uk 


\title{
Turning the tables on obesity: young people, IT and social movements
}

\author{
Charoula K. Nikolaou, Thomas N. Robinson, Kyra A. Sim and Michael E. J. Lean
}

\begin{abstract}
Despite the rising incidence of childhood obesity, international data from EUROSTAT show that the prevalence of obesity at ages 15-19 years remains $<5 \%$, which offers an important opportunity for preventing subsequent adult obesity. Young people engage poorly, even obstructively, with conventional health initiatives, and are often considered 'hard-to-reach'. However, when approached in the language of youth, via IT, they express great concern, and unwanted weight gain in young people can be prevented by age-appropriate independent, online guidance. Additionally, when shown online how 'added value' for industry can generate consumer harms as free market 'externalities', and how obesogenic 'Big Food' production and distribution incur environmental and ethical costs, they make lasting behavioural changes that attenuate weight gain. This evidence offers a novel approach to obesity prevention, handing the initiative to young people themselves, and supporting them with evidence-based methods to develop, propagate and 'own' social movements that can simultaneously address geo-political concerns of youth and obesity prevention.
\end{abstract}

\section{Introduction}

Conventional government-led initiatives to promote population health have not generated any reversal of obesity or related adverse health trends, and in 2014 the United Nations (UN) Secretary noted lack of progress towards the targets set by the 2011 political declaration of the $\mathrm{UN}$ on non-communicable diseases $(\mathrm{NCDs})^{1,2}$. Among the factors that contributed to the slow progress were insufficient funding and poor understanding of NCDs from the public that led to insufficient civil engagement with the problem ${ }^{3,4}$. The intergovernmental negotiations that led to adopting the 2030 agenda for Sustainable Development Goals (SDGs) in 2015 involved all key stakeholders, including the civil society. The UN Secretary recommended to "keep the doors open for civil society" for successfully moving the agenda beyond $2015^{5}$. The importance of engaging civil society is also recognised by developing countries that are hit the hardest by $\mathrm{NCDs}^{6}$, for example by a citizen's forum for health participation and 
ownership in Mongolia ${ }^{7}$. Here, we describe a novel approach to tackling the obesity epidemic, identifying the greatest need for action among young people before clinical problems emerge, and harnessing the potential resource offered by young people themselves to drive change through social movements and social media.

The largest generation of young people (10-24 years old) in human history, now some 1.8 billion globally ${ }^{8}$, will soon become the world's workforce and parents. With preventable chronic diseases now dominating health ${ }^{9}$ and escalating health-care budgets ${ }^{10}$, how young people lead their lives, through lifestyle choices or life circumstances, will determine their health and shape future families, communities and nations. Tackling NCDs, initially a purely health issue, is now part of the UN SGDs ${ }^{11}$. In addition, the UN further committed to tackling NCDs during the Third UN High-Level Meeting on NCDs in 2018 and called for novel approaches $^{12}$.

The two leading preventable causes of chronic diseases are obesity and smoking ${ }^{13}$. Conventional health education has struggled to fully address either obesity or smoking, and both are heavily influenced by commercial interests. However, whereas smoking cessation initiatives in adulthood have been fairly successful, it is very hard to achieve sustained weight loss in later life. Adolescence and early adulthood (broadly spanning 12-24 years of age) is the life-period with the most rapid weight gain, progressing for many to adult obesity ${ }^{14-16}$. With limited long-term treatment and prevention success, particularly among children ${ }^{17-24}$, establishing effective prevention of unwanted and ultimately damaging weight gain in young people is vital.

No country has ever reported a statistically significant fall in obesity ${ }^{25}$. However smoking has fallen dramatically among young people (15-24 years old) globally from $19.1 \%$ in 2000 to $14.3 \%$ in $2015^{26}$, perhaps not just through decades of conventional health education and taxation, but also by mobilizing support for regulatory and legislative actions and by revealing the commercial practices and exploitation by the tobacco industry which marginalise smoking as 'un-cool' for young people. As an example, the 'FinishIt' campaign exposed the strategies behind 'Big Tobacco' and was associated with reduced youth smoking from $23 \%$ in 2000 to $6 \%$ in 2014 among 8,331 Florida youths ${ }^{27}$. Similarly, drinking alcohol is increasingly being scorned by some youth sectors as a behaviour of older generations, and decreased statistically significantly between 2002 and 2014 among both boys and girls in 36 countries in the European region ${ }^{28}$. A similar picture is revealed by the Australian Bureau of 
Statistics, which shows that in 2014, alcohol consumption reached its lowest point since the 1960 s, a reduction driven by youths ${ }^{29}$. This reduction cannot be fully explained by policy changes and started before the introduction of the alcopops tax in Australia. We should note that the drops in alcohol and tobacco use in higher-income countries are not matched in many middle-income and lower-income countries ${ }^{30}$.

\section{Critical periods for weight-gain}

Adolescence and early adulthood is marked by rapid weight gain for many, and interventions have so far proved largely ineffective ${ }^{15,31,32}$. Underlying genetic, epigenetic and environmental factors contribute to worrying increases in overweight during childhood, but a BMI $>30 \mathrm{~kg} / \mathrm{m}^{2}$ (the adult criterion for 'obesity') is still fairly uncommon at the transition into independent adulthood; that is, aged 16-21 years in most countries ${ }^{33}$. While children are still growing, body fat levels are generally lower than in adulthood, and childhood obesity is identified based on centiles for age. Although childhood obesity, with its different criteria, affects somewhat greater numbers (the global prevalence of obesity in children using the International Obesity Task Force criteria is $5 \%{ }^{33}$.In Europe, only $3.1 \%$ of $15-19$ year olds have a BMI $>30 \mathrm{~kg} / \mathrm{m}^{2}$, but that prevalence rises almost threefold by age 25-29 years, ultimately to much higher levels by age 60-64 years (Table 1) ${ }^{34}$. Data collected by the Institute for Health Metrics and Evaluation (IHME) shows the same pattern for countries outside the EU (Table 1). Thus in the USA, 13.4\% of young people aged 15-19 years old have a BMI $>30 \mathrm{~kg} / \mathrm{m}^{2}$, rising to $25.2 \%$ at age $25-29$ years and to over $30.0 \%$ by middleage $^{35}$. Similar situations are seen in Mexico, Australia, Canada, Brazil, New Zealand and Russia (Figure 1) ${ }^{35}$. Data from a number of countries also show how more recent birth cohorts (1998-2001) are more likely to become obese, and at earlier ages, than older birth cohorts (1978-1981) ${ }^{36,37}$. These data demonstrate the need for action, but also offer a window of opportunity to intervene before adult obesity becomes established.

Using conventional health promotion approaches, public health agencies have a poor record of engagement with adolescents and young adults, sometimes leading to these groups being ignored or avoided as specific targets for interventions. They have been viewed as 'hard-toreach', questioning or rejecting didactic advice, sometimes dismissed as irresponsible or uncaring towards health, even deliberately obstructive ${ }^{38}$. These failures and prejudices might have arisen through failure to tap in to the changing contemporary language and symbolisms of young people, and their social and political priorities. Young people do 
react strongly to questions of fairness, perceived injustice and exploitation, identify with ethical and environmental concerns and can unite powerfully to generate change through social movements.

\section{[H1] Social movements}

Social movements, purposeful organized collective groups working toward a common goal of change, are not new. They have been traced back to the 1760 s, related to the emergence of rapidly published newspapers and broadsheets, and to coffee or tea-shop cultures ${ }^{39}$. Young people have often been at the forefront of social change. The massive Hippie counter-culture movement was pioneered by youth, advocating since the 1960s for world peace and opposing commercial exploitation and continuing for almost 60 years ${ }^{40}$. Young people were important in initiating and sustaining the Civil Rights movement in the 1950s, to end race segregation and establish pioneering equal-rights legislation in the USA for African Americans ${ }^{41}$. The growth of social media has now greatly increased the capacity of the 'digital native' generation, familiar with the web and internet devices, to propagate and amplify social movements for change.

Examples from the past few years include the increasingly organized adolescents' efforts to change US gun laws, Hong Kong's 'Umbrella' political movement opposing selective prescreening of election candidates and notably the international students' strikes for climate change, initiated by the Swedish teenager Greta Thunberg ${ }^{42}$. The International Youth Climate movement contributes to Climate Summits, negotiating sustainability issues ${ }^{43}$. The demographic spread of social movements is complicated and probably topic-specific to some degree, but they have the capacity to extend both upwards and downwards across educational and social gradients, and internationally. The 'Arab Spring' was also the result of a large social movement, followed by further action in other countries in Africa, such as the university students in Malawi protesting against the government for intimidating a professor who discussed the Arab Spring in class ${ }^{44}$. Other social movements with potential health and wellbeing implications for young people include the Indigenous Lands Rights movement in Brazil that has resulted in political changes in the country ${ }^{45}$, and the Honduras Environmental Movement campaigning for environmental justice ${ }^{46}$.

In step with other social movements, young people concerned about social justice now have the capacity to generate new pressure to change the current inactivity-promoting, social marketing and obesogenic environments, and there is some evidence that this issue has 
traction among young people. For instance, a web-based randomized trial among 20,000 young adult university students found evidence for sustained behavioural change using both an overt 'Rational model' intervention, aimed at helping to understand food, energy balance and avoid weight gain, and a 'Stealth Intervention Model' ${ }^{47}$. The latter model covertly guided participants towards healthier food choices by focusing on the commercial, political and marketing methods and environmental impacts of 'Big Food' to provide the 'western' diets that have generated epidemics of obesity and type 2 diabetes mellitus, using food production and farming patterns that also increase greenhouse gas production. In this study, the control group gained about $2.0 \mathrm{~kg}$ over 9 months (which is usual among young adults ${ }^{15}$ ), whereas both intervention groups avoided weight gain ${ }^{48}$. Sustained avoidance of weight gain from online 'Rational model' material is valuable, but the equal success of a 'Stealth intervention', focused on geo-political aspects of the food industry, opens new channels for obesity prevention. Similarly, a previous study found improved dietary habits among university students studying 'Food and Society' (addressing issues such as ethics, environment, labour, trade and marketing related to food, but not including health-related or nutrition-related topics), compared with students with similar diets and attitudes at baseline who took classes in 'Health and Biology' specifically related to obesity ${ }^{49}$.

A randomized controlled trial of US Girl Scouts found that an intervention focusing on environmental energy conservation through diet and transportation choices produced greater change in obesity-related food and transportation-related behaviours than an intervention focusing on residential energy conservation ${ }^{50}$. Broadening obesity prevention efforts beyond the 'rational' battle of willpower can re-position 'healthy eating' as legitimate for youth rebellion against the current industrialised food environment. Another randomized controlled trial among eighth-grade children (14-year-olds) supported a treatment that framed 'healthy eating' as consistent with adolescent values of autonomy from adult control, and pursuit of social justice $^{51}$. Online focus groups have found that young people, consistently from six countries, would value independent guidance, and that they are willing to change personal obesogenic food choices and inactivity to avoid excess weight-gain and protect the environment ${ }^{52}$.

\section{[H1] The imaginative way forward}

New components for multifaceted approaches, using both sides of the energy balance equation, are needed to oppose the unwanted excess weight gain that is now usual among 
young people. Obesity has sometimes been considered separately from other major health challenges, but is now viewed as the main driver for all major NCDs, many of which are also linked to undernutrition and climate change, within a complex human and environmental syndemic, and demanding common actions ${ }^{53}$. Linking two prominent concerns by exposing certain globalised commercial and agricultural practices as exploitative or environmentally damaging as well as obesogenic, might stimulate changes in food choices, and thereby food provision in a demand-led market, towards more healthful vegetable-based diets. This change would simultaneously reduce greenhouse gas emissions and help reduce heart disease and obesity $^{54}$.

Young people can also address inactivity. Sport has been promoted by 'Big Food' as a way to counteract excessive calorie intakes. While valuable and pleasurable, exercise alone is insufficient to maintain a weight in the normal BMI range, and few people maintain sports deep into adult life. Inactivity, rather than lack of sporting exertion, is emerging as the real problem. Transport and planning policies must encourage multiple smaller behavioural shifts with cumulative benefits, such as urban design that reduces the need for driving and promotes active travel with lower environmental impacts, for example through bicycle-sharing schemes. Changing demographics, views and attitudes have already generated considerable falls in car usage and a shifting driving culture among young people in high-income countries $^{55}$. There is scope to mount social movements among young people that will further decrease inactivity, such as by reclaiming public spaces, and reacting against unthinking political support for the motor industry that has made walking or cycling unappealing in most US cities and many others around the world ${ }^{56}$.

Varying social, cultural and political conditions across communities, at different stages of globalisation and of the obesity epidemic, will influence the extent of uptake and impact of any social movement. However, the very consistent themes that emerged in online focus groups among young people in six countries suggests that these issues are similar across communities $^{52}$. The participants probably had fairly high educational levels but covered various ethnic groups in countries that all had English as the first language (UK, Singapore and New Zealand) or a dominant second language (Finland, Greece and Belgium) in young people. We also included participants who were unemployed or outside higher education, particularly from Greece where in 2017, when the study was conducted, youth unemployment was $43.5 \%$ after the financial crisis of 2009 , and children have grown up to 
become adults in this environment ${ }^{57}$. We found no differences in their interests: the concerns about weight gain and obesity, and over geopolitical issues, do seem to extend to all sectors of youth.

Much less evidence is available about social movements in low and middle income countries (LIMCs). However, many young people in LIMCs have high access to modern technologies and have already started movements, such as the 'Walk to Work' movement in Uganda as a result of the high fuel and food-staples prices ${ }^{58}$. Eating, smoking and drinking behaviours of young people in LIMCs will be under rather different influences than those of young people in high-income countries, but as overweight and obesity start to become more common, in parallel with rising educational standards, a 'global' social movement might well be adapted to be effective in opposing social marketing by 'Big Food' and other obesogenic industries in all countries.

\section{Social movements for health gain}

An effective social movement to oppose obesity is unlikely to arise by chance, but can be created and nurtured intentionally. The Slow Food Movement is a relevant example, firstly in its opposition to fast food, (which is implicated in the obesity and type 2 diabetes mellitus epidemics ${ }^{59,60,61,62)}$, and secondly as an example of a carefully managed social movement. Dating from 1989, it was founded 'to prevent the disappearance of local food cultures and traditions, counteract the rise of fast life and combat people's dwindling interest in the food they eat ${ }^{63}$. It has survived many decades and, supported by magazines, websites and prominent restaurants, had substantial influence with more than 100,000 members in 132 countries $^{64}$.. The movement grew from initial origins in fairly highly educated sectors, expanding from passionate interests in food authenticity to embrace biodiversity on the global stage. It now has a sophisticated organisation and staffed offices located in five continents, but its reach is somewhat limited to the middle aged and middle class, so is not directed towards obesity prevention in the whole population.

Social movements are considered to have a four-stage natural history to empower citizens to identify and claim social justice and health They are initiated in a preliminary stage when specific information or ideas are shared, capturing the awareness of natural leaders who come together in a second coalescence stage, to start to organise and disseminate. To become 
durable and effective, a social movement then needs to be nurtured in a more formally organised way, the institutionalisation stage, until ultimately (successful or otherwise) it falls into the decline stage ${ }^{65}$.

The measures needed to build and support movements for social change have been summarised by Ganz ${ }^{66}$ as five 'Core Practices' (Box 1). To generate wide and lasting traction, a social movement must resonate with other topical noble causes; for example, currently, environmental preservation and social justice, and then circulate in accessible forms. Therefore, to oppose obesity, a movement must resonate and circulate among young people in the language of young people. Changing eating and physical activity behaviours seem to be very possible targets, as they can be viewed as integral to social justice, and to environmental, ethical and political goals. Raising awareness about how commercial interests can impinge upon consumer freedoms and health' could add valuably to changing behaviours at a population level. However, a few potential hazards exist. Fears about perceived personal sensitivities over body weight, and anxieties about provoking eating disorders, might have obstructed some conventional efforts towards preventing unwanted weight gain, but no clear link has emerged ${ }^{67}$.

Young people themselves are well-placed to propagate and amplify engagement with healthdirected social movements using social media to generate and sustain change. The anonymity of online programmes and being part of a social movement offer advantages. Unlike traditional top-down public health interventions, online programmes can be framed around two important and rather different conceptual approaches ${ }^{48}$ 'Food literacy' helps individuals negotiate the current obesogenic environment. Whereas 'food citizenship' raises awareness about exploitation of vulnerable young people, for example by retail and catering marketing, and exploitation of vulnerable environments through the demands of 'Big Food' on modern agriculture. Adopting these principles will help generate more thoughtful eating behaviours and alter food choices, which will ultimately shift food supply and production methods. Some adjustments might be necessary to promote food literacy and citizenship in low socioeconomic groups to avoid exacerbating inequalities. The same changes will simultaneously protect the planet and reduce unwanted weight-gain to improve long-term health. It is hard at this stage to pre-empt the exact path that a social movement will take. In general, the food industry is always primarily responsive to changes in demand (although it invests very large amounts in efforts to minimise changes in demand ${ }^{68}$ ). A secondary 
influence on food supply emerges once regulatory and fiscal measures are introduced by governments. When social movements start to influence voting intentions, introducing these measures becomes possible.

\section{[H1] Conclusions}

Despite reasonably complete understanding of its epidemiology and causal factors, we lack effective solutions to prevent the inexorable rise in overweight and obesity, in efforts to reach the UN 2030 SDGs $^{69}$. Thinking 'outside the box' over food and nutrition is required, over a timescale to complement the Global Action Plan on Physical Activity 2018-2030 ${ }^{70}$. Dr Sania Nishtar, co-chair of the WHO Independent High-level Commission on NCDs said in the UN assembly in September 2018 "the public health community must actively participate in the societal transformations, especially in the area of digital technologies, to ensure that they are used to advance the NCDs agenda and intergrade new approaches to existing public health promotion activities",71.

The greatest population health gains in relation to obesity will be from behaviour changes among young people, and the IT revolution and rise of social media present new opportunities to work closely with young people. We need a strong, safe and sustainable food industry but all would benefit from a less obesogenic food environment, coupled with measures to enhance physical activity such as safe walking and cycling tracks beside all roads and green urban walk-ways to de-normalize inactivity. The challenge will be to redirect some funding towards an entirely new approach, to nurture and build a social movement against obesity, at the same time favouring reduced greenhouse gas production. Without changes to structural and environmental factors, conventional health promotion has not proved sufficient against obesity.

Low-cost, wide-reach, web-based eHealth approaches for 'food citizenship' and 'food literacy' could be harnessed to drive social movements that reverse the obesity epidemic. Further, piggybacking on existing youth-led social movements that include behavioural goals that influence obesogenic behaviours related to eating and transportation, such as movements for environmental sustainability, social justice, workers' rights and animal welfare, might synergize actions and enhance their effectiveness ${ }^{72}$. The obesity and chronic disease epidemic can only be reversed by preventive medicine, summarised in 1945 as concerned with "living conditions, hygiene, and common-sense" (Noel Coward/David Lean, Brief Encounter, 1945, 
using the WHO definition of "hygiene" as referring to all conditions and practices that help to maintain health, including diet and lifestyle as well as cleanliness).

It is often commented that most of the great advances in public health have emerged not through convincing specific evidence for effectiveness, but from application of clear-sighted observation and common sense. Harnessing the energy and communication methods of young people offers a real likelihood of success. We should not be frightened to offer young people themselves the chance to shake things up, using their IT and social media skills, to fix this problem that successful economies have created and manifestly failed to fix. We might recall the words of JM Barrie, author of Peter Pan: "Youth have for too long left exclusively in our hands the decisions in national matters that are more vital to them than to us."72.

Charoula K. Nikolaou ${ }^{1,2}$, Thomas N. Robinson ${ }^{3,4}$, Kyra A. Sim ${ }^{5}$ and Michael E. J. $\operatorname{Lean}^{6 *}$

${ }^{1}$ Division of Biostatistics and Bioinformatics, Graduate School of Public Health, St Luke's International University, Tokyo, Japan.

${ }^{2} \mathrm{SSH} / J U R I$ - Institut pour la recherche interdisciplinaire en sciences juridiques (JUR-I), Catholic University of Louvain, Louvain-la-Neuve, Belgium.

${ }^{3}$ Stanford Solutions Science Lab, Departments of Pediatrics and of Medicine, Stanford University, Stanford, CA, USA.

${ }^{4}$ Lucile Packard Children's Hospital, Palo Alto, CA, USA.

${ }^{5}$ The Boden Institute, Charles Perkins Centre, The University of Sydney, NSW, Australia

${ }^{6}$ Human Nutrition Section, College of Medical, Veterinary and Life Sciences, University of Glasgow, Glasgow Royal Infirmary, Glasgow, UK.

*email: mike.lean@glasgow.ac.uk 


\section{References}

1. United Nationals General Assembly Political Declaration of the High-Level Meeting of the General Assembly on the Prevention and Control of NonCommunicable

Diseases https://www.un.org/en/ga/ncdmeeting2011/documents.shtml (UN, 2011).

2. World Health Assembly Follow-up to the Political Declaration of the High-Level Meeting of the General Assembly on the Prevention and Control of Noncommunicable

https://apps.who.int/gb/ebwha/pdf_files/WHA66/A66_R10-en.pdf(WHA, 2013).

3. Horton, R. NCDs - why are we failing? Lancet 390, 346 (2017).

4. Buse, K., Tanaka, S. \& Hawkes, S. Healthy people and healthy profits? Elaborating a conceptual framework for governing the commercial determinants of noncommunicable diseases and identifying options for reducing risk exposure. Glob. Health 13, 34 (2017).

5. United Nations Sustainable Development Goals Civil Society \& Other Stakeholders Leaving No One Behind When Implementing the Agenda 2030 https://sustainabledevelopment.un.org/content/documents/9486ANilo\%20Civil\%20 Society\%20\&\%20Other\%20Stakeholders.pdf (UN, 2015).

6. Allen, L. et al. Poverty and risk factors for non-communicable diseases in developing countries: a systematic review. Lancet 388, S17 (2016).

7. United Nations General Assembly High-Level Meeting on Non-Communicable Diseases Urges National Targets, Global Commitments to Prevent Needless Loss of Life https://www.un.org/press/en/2014/ga11530.doc.htm (UN, 2014).

8. Patton, G.C. et al. Our future: a Lancet commission on adolescent health and wellbeing. Lancet 387, 2423-2478 (2016). 
9. Bennett, J.E. et al. NCD Countdown 2030: worldwide trends in non-communicable disease mortality and progress towards Sustainable Development Goal target 3.4. Lancet 392, 1072-1088 (2018).

10. Allen, L.N. Financing national non-communicable disease responses. Glob. Health Action 10, 1326687 (2017).

11. United Nations Sustainable Development Goals About the Sustainable Development Goals https://www.un.org/sustainabledevelopment/sustainable-development-goals/ (UN, 2015).

12. World Health Organization Third United Nations High-level Meeting on NCDs https://www.who.int/ncds/governance/third-un-meeting/en/ (WHO, 2018).

13. World Health Organization Obesity, High Blood Pressure, High Cholesterol, Alcohol and Tobacco: The World Health Organization's Response http://www.who.int/whr/media_centre/factsheet3/en/ (WHO, 2013).

14. Lanoye, A., Brown, K.L. \& LaRose, J.G. The transition into young adulthood: a critical period for weight control. Curr. Diab. Rep. 17, 114 (2017).

15. Nikolaou, C.K., Hankey, C.R. \& Lean, M.E. Weight changes in young adults: a mixed-methods study. Int. J. Obes. 39, 508 (2015).

16. Bergh, I.H., Skare, Ø., Aase, A., Klepp, K.I. \& Lien, N. Weight development from age 13 to 30 years and adolescent socioeconomic status: the Norwegian Longitudinal Health Behaviour study. Int. J. Public Health 61, 465-473 (2016).

17. Foster, B.A., Farragher, J., Parker, P. \& Sosa, E,T. Treatment interventions for early childhood obesity: a systematic review. Acad. Pediatr. 15, 353-361 (2015).

18. Kokkvoll, A.S. et al. No additional long-term effect of group versus individual family intervention in the treatment of childhood obesity - a randomised trial. Acta Paediatr. 109, doi: 10.1111/apa.14916 (2019).

19. O’Connor, E.A., Evans, C.V., Burda, B.U., Walsh, E.S., Eder, M. \& Lozano, P. Screening for obesity and intervention for weight management in children and adolescents: evidence report and systematic review for the US Preventive Services Task Force. JAMA. 317, 2427-2444 (2017).

20. Colquitt, J. et al. Diet, physical activity, and behavioural interventions for the treatment of overweight or obesity in preschool children up to the age of 6 years. Cochrane Database Syst. Rev. 3, CD012105 (2016). 
21. Adab, P. et al. Effectiveness of a childhood obesity prevention programme delivered through schools, targeting 6 and 7 year olds: cluster randomised controlled trial (WAVES study). BMJ. 360, k211 (2018).

22. Kipping, R.R. et al. Effect of intervention aimed at increasing physical activity, reducing sedentary behaviour, and increasing fruit and vegetable consumption in children: active for Life Year 5 (AFLY5) school based cluster randomised controlled trial. BMJ. 348, g3256 (2014).

23. Lloyd, J. et al. Effectiveness of the Healthy Lifestyles Programme (HeLP) to prevent obesity in UK primary-school children: a cluster randomised controlled trial. Lancet Child Adolesc. Health. 2, 35-45 (2018).

24. Waters, E. et al. Interventions for preventing obesity in children. Cochrane Database Syst. Rev. 12, CD001871 (2011).

25. $\mathrm{Ng}$, Marie, et al. "Global, regional, and national prevalence of overweight and obesity in children and adults during 1980-2013: a systematic analysis for the Global Burden of Disease Study 2013." The lancet 384.9945: 766-78 (2014).

26. WHO global report on trends in prevalence of tobacco smoking 2000-2025, second edition. Geneva: World Health Organization; Licence: CC BY-NC-SA 3.0 IGO. (WHO, 2018).

https://apps.who.int/iris/bitstream/handle/10665/272694/9789241514170eng.pdf?ua $=1$

27. Vallone, D. et al. Evidence of the impact of the truth FinishIt campaign. Nicotine Tob. Res.20, 543-551 (2018).

28. World Health Organization Adolescent Alcohol-related Behaviours: Trends and Inequalities in the WHO European Region, 2002-2014 (WHO, 2018).

29. Australian Bureau of Statistics 4307.0.55.001 - Apparent Consumption of Alcohol, Australia, 2013-14 https://www.abs.gov.au/AUSSTATS/abs@.nsf/Lookup/4307.0.55.001Main+Featur es12013-14?OpenDocument (ABS, 2015).

30. The Economist How to Cut Smoking in Poor Countries https://www.economist.com/leaders/2017/06/01/how-to-cut-smoking-in-poorcountries (The Economist, 2017).

31. Lanoye, A., Brown, K.L. \& LaRose, J.G. The transition into young adulthood: a critical period for weight control. Curr. Diab. Rep. 17, 114 (2017). 
32. Laska MN, Pelletier JE, Larson NI, Story M. Interventions for weight gain prevention during the transition to young adulthood: a review of the literature. $J$. Adolesc. Health 50, 324-333 (2012).

33. GBD 2015 Obesity Collaborators. Health effects of overweight and obesity in 195 countries over 25 years. N. Engl. J. Med. 377, 13-27 (2017).

34. Eurostat Overweight and obesity - BMI statistics https://ec.europa.eu/eurostat/statisticsexplained/index.php/Overweight_and_obesity_-_BMI_statistics (Eurostat, 2014)

35. Institute for Health Metrics and Evaluation. Institute for Health Metrics and Evaluation http://www.healthdata.org/ (IHME, 2013).

36. Australian Institute of Health and Welfare A Picture of Overweight and Obesity in Australia (AIHW, 2017 https://www.aihw.gov.au/getmedia/172fba28-785e-4a08ab37-2da3bbae40b8/aihw-phe-216.pdf.aspx?inline=true Page 12.

37. Li, L., Hardy, R., Kuh, D., Lo Conte. R. \& Power, C. Child-to-adult body mass index and height trajectories: a comparison of 2 British birth cohorts. Am. J. Epidemiol. 168, 1008-1015 (2008).

38. Spencer, G. Empowerment, Health Promotion and Young People: A Critical Approach (Routledge, 2013).

39. Tilly, C. As Sociology Meets History (Academic Pr., 1981

40. Howard, J.R. The flowering of the hippie movement. Ann. Am. Acad. Pol. Soc. Sci. 382, 43-55 (1969).

41. Fairclough, A. Historians and the civil rights movement. J. Am. Stud. 24, 387-398.

42. The Guardian Greta Thunberg, Schoolgirl Climate Change Warrior: 'Some people Can Let Things Go. I Can't' https:/www.theguardian.com/world/2019/mar/11/greta-thunberg-schoolgirlclimate-change-warrior-some-people-can-let-things-go-i-cant (The Guardian, 2019).

43. International Youth Climate Movement. YOUNGO. https://youthclimatemovement.wordpress.com/youngo/ (The international Youth Climate Movement, 2019).

44. Aidi, H. Africa's New Social Movements: A Continental Approach https://www.africaportal.org/publications/africas-new-social-movementscontinental-approach/ (Africa Portal, 2018). 
45. Carvalho, G.O. The politics of indigenous land rights Brazil. Bull. Lat. Am. Res. 19, 461-478 (2000).

46. Pearce, F. In Honduras, Defending Nature is a Deadly Business https://e360.yale.edu/features/honduras-berta-caceres-murder-activistsenvironmentalists-at-risk (E360, 2017)

47. Robinson, T.N. in. Eating Disorders and Obesity: A Comprehensive Handbook (Brownell, K.D. \& Walsh, B.T. ed.) 609-613 (Guilford Publications, 2017).

48. Nikolaou, C.K., Hankey, C.R. \& Lean, M.E. Elearning approaches to prevent weight gain in young adults: a randomized controlled study. Obesity 3: 2377-2384 (2015).

49. Hekler, E.B., Gardner, C.D. \& Robinson, T.N. Effects of a college course about food and society on students' eating behaviors. Am. J. Prev. Med. 38, 543-547 (2010).

50. Boudet, H., Ardoin, N.M., Flora, J., Armel, K.C., Desai, M. \& Robinson, T.N. Effects of a behaviour change intervention for Girl Scouts on child and parent energy-saving behaviours. Nat. Energy 1, 16091 (2016).

51. Bryan, C.J. et al. Harnessing adolescent values to motivate healthier eating. Proc. Natl. Acad. Sci. 113, 10830-10835 (2016).

52. Nikolaou CK, Tay Z, Leu J, Rebello SA, Te Morenga L, Van Dam RM, Lean MEJ, Young People's Attitudes and Motivations Toward Social Media and Mobile Apps for Weight Control: Mixed Methods Study, JMIR Mhealth Uhealth 2019;7(10):e11205, URL: $\quad$ https://mhealth.jmir.org/2019/10/e11205, DOI: $10.2196 / 11205$

53. Swinburn, B.A. et al. The global syndemic of obesity, undernutrition, and climate change: The Lancet Commission report. Lancet 393, 791-846 (2019).

54. Scarborough, P. et al. Dietary greenhouse gas emissions of meat-eaters, fish-eaters, vegetarians and vegans in the UK. Clim. Change 125, 179-192 (2014).

55. Polzin, S., Chu, X. \& Godfrey, J. The impact of millennials' travel behavior on future personal vehicle travel. Energy Strateg. Rev. 5, 59-65 (2014).

56. The forgotten history of how automakers invented the crime of "jaywalking". https://www.vox.com/2015/1/15/7551873/jaywalking-history (Vox, 2015).

57. World Bank, Youth Unemployment Rate for Greece [SLUEM1524ZSGRC], retrieved from FRED, Federal Reserve Bank of St. Louis; https://fred.stlouisfed.org/series/SLUEM1524ZSGRC, October 10, 2019 
58. Uganda walk-to-work protests kick up the dust. https://www.aljazeera.com/indepth/features/2011/04/201142831330647345.html. (Aljazeera, 2011)

59. Rosenheck, Robert. "Fast food consumption and increased caloric intake: a systematic review of a trajectory towards weight gain and obesity risk." Obesity reviews 9.6: 535-547. (2008)

60. Fraser, Lorna K., et al. "Fast food and obesity: a spatial analysis in a large United Kingdom population of children aged 13-15." American journal of preventive medicine 42.5: e77-e85.(2012).

61. Astrup, Arne. "Super-sized and diabetic by frequent fast-food consumption?." The Lancet 365.9453: 4-5.(2005).

62. Pereira, Mark A., et al. "Fast-food habits, weight gain, and insulin resistance (the CARDIA study): 15-year prospective analysis." The lancet 365.9453: 36-42.(2005).

63. Slow Food About Us https://www.slowfood.com/about-us/ (Slow Food, 2015).

64. Analysis of the Slow Food movement impact on the farmers and rural areas' sustainable development. https://core.ac.uk/download/pdf/17332798.pdf. $\mathrm{PhD}$ thesis, page 11. (2013).

65. Tilly, C Social Movements and National Politics https://deepblue.lib.umich.edu/bitstream/handle/2027.42/50971/197.pdf?sequence= $1 \&$ isAllowed $=\mathrm{y}$ (University of Michigan, 1979).

66. Ganz, M. Handbook of Leadership Theory and Practice: A Harvard Business School Centennial Colloquium (Harvard Business School Publishing, 2010). Chapter 19: Leading Change: Leadership, Oragnization, and Social Movements, pages 6-35

67. Neumark-Sztainer, D. Can we simultaneously work toward the prevention of obesity and eating disorders in children and adolescents? Int. J. Eat. Disord. 38, 220-227 (2005).

68. Koplan, Jeffrey P., and Kelly D. Brownell. "Response of the food and beverage industry to the obesity threat." Jama 304.13 (2010): 1487-1488.

69. Bluher, M. Obesity: global epidemiology and pathogenesis. Nature Rev. Endocrinol. 15, 288-298 (2019).

70. World Health Organization Global Action Plan on Physical Activity 2018-2030: More Active People for a Healthier World (WHO, 2018) Licence: CC BY-NC-SA 3.0 IGO.

71. United Nations Summary by the President of the General Assembly of the Interactive Hearing as Part of the Preparatory Process for the Third High-level Meeting on the Prevention and Control of Non-communicable Diseases 
https://www.un.org/pga/72/wp-content/uploads/sites/51/2018/08/NCD-9August.pdf (UN, 2018).

72. Robinson, T.N. Save the world, prevent obesity: piggybacking on existing social and ideological movements. Obesity 18, S17-S22 (2010).

73. JM Barrie, author of Peter Pan. Courage: The Rectorial Address Delivered by James M. Barrie at St. Andrew's University, May 3, 1922. https://www.onlineliterature.com/barrie/2088/accessed 30 May 2019)

\section{Acknowledgements}

We thank Professor Harry Rutter for his many insightful comments on earlier drafts. C.K.N acknowledges the support of a Marie-Curie-Move-in Louvain Fellowship from the European Union.

\section{Author contributions}

C.K.N. and M.J.L. contributed equally to all aspects of the manuscript. T.N.R. contributed to discussion of the content, wrote the article and reviewed and edited the manuscript before submission. K.A.S. contributed to discussion of the content, wrote the article and reviewed and edited the manuscript before submission.

\section{Competing interests}

The authors declare no competing interests.

\section{Peer review information}

Nature Reviews Endocrinology thanks L. Baur and the other, anonymous, reviewer(s) for their contribution to the peer review of this work.

Publisher's note

Springer Nature remains neutral with regard to jurisdictional claims in published maps and institutional affiliations. 
Table 1: Prevalence of BMI $>30 \mathrm{~kg} / \mathrm{m}^{2}$ (in 2013-2015) in 35 countries

\begin{tabular}{|c|c|c|c|c|c|c|}
\hline \multirow[t]{2}{*}{ Country } & \multicolumn{2}{|c|}{ 15-19 year olds $(\%)$} & \multicolumn{2}{|c|}{ 25-29 year olds $(\%)$} & \multicolumn{2}{|c|}{$60-64$ year olds $(\%)$} \\
\hline & Eurostat & IEHM & Eurostat & IEHM & Eurostat & IEHM \\
\hline Austria & 2.8 & 5.9 & 10.9 & 8.4 & 21.3 & 20.4 \\
\hline Belgium & 3.0 & 3.6 & 10.3 & 11.8 & 19.5 & 21.8 \\
\hline Bulgaria & 1.5 & 3.9 & 5.9 & 8.5 & 26.7 & 19.6 \\
\hline Croatia & 1.3 & 3.9 & 7.5 & 10.3 & 24.2 & 23.7 \\
\hline Cyprus & 3.6 & 6.8 & 5.5 & 14.1 & 26.6 & 25.4 \\
\hline Czech Republic & 2.1 & 4.1 & 7.7 & 8.4 & 30.8 & 23.2 \\
\hline Denmark & 4.4 & 5.8 & 10.2 & 11 & 16.9 & 19.7 \\
\hline Estonia & 2.7 & 4.6 & 9.1 & 10.9 & 26.6 & 26.5 \\
\hline Finland & 4.7 & 4.8 & 12.8 & 13 & 19.6 & 22.2 \\
\hline France & 3.2 & 4.9 & 9.1 & 11.3 & 22.8 & 19.8 \\
\hline Germany & 3.4 & 5.2 & 8.9 & 11.3 & 24.3 & 26 \\
\hline Greece & 2.3 & 4.4 & 7.6 & 10.2 & 25.3 & 20.7 \\
\hline Hungary & 5.0 & 4.5 & 10.0 & 12.1 & 29.5 & 26.7 \\
\hline Iceland & 5.9 & 6.4 & 14.5 & 18.5 & 24.4 & 27.3 \\
\hline Ireland & 6.7 & 5.2 & 16.5 & 12.7 & 23.2 & 24.9 \\
\hline Italy & 2.1 & 4 & 4.6 & 8.5 & 15.4 & 20.8 \\
\hline Latvia & 3.3 & 3 & 7.1 & 9.4 & 33.5 & 26.8 \\
\hline Lithuania & 1.3 & 4.8 & 5.1 & 10.4 & 29.4 & 26.4 \\
\hline Luxembourg & 2.8 & 8 & 9.6 & 16.8 & 19.3 & 24.4 \\
\hline Malta & $6 \cdot 8$ & 8.1 & $20 \cdot 2$ & 17.4 & 33.9 & 26.9 \\
\hline Netherlands & 3.1 & 2.7 & 8.3 & 8.1 & 17.3 & 14.3 \\
\hline Norway & 2.8 & 5.1 & 9.3 & 12 & 13.1 & 16.6 \\
\hline Poland & 2.5 & 3.7 & 6.3 & 9.6 & 27.5 & 24.1 \\
\hline Portugal & 4.6 & 4.8 & 8.8 & 12.3 & 27.6 & 23.1 \\
\hline Romania & 0.9 & 4.4 & 3.5 & 8.3 & 16.1 & 21.6 \\
\hline Slovenia & 3.6 & 3.1 & 6.5 & 10.9 & 24.7 & 23.8 \\
\hline Slovakia & 2.8 & 3.3 & 7.0 & 8.5 & 31.8 & 26 \\
\hline Spain & 2.0 & 3.8 & 11.2 & 10.6 & 26.6 & 23.7 \\
\hline Sweden & 4.3 & 3.3 & 10.2 & 13 & 19.1 & 18.8 \\
\hline UK & 5.7 & 6.5 & 14.0 & 16.2 & 25.4 & 29.3 \\
\hline USA & NA & 13.4 & NA & 25.2 & NA & 33.7 \\
\hline Australia & NA & 5.3 & NA & 17.1 & NA & 29.6 \\
\hline New Zealand & NA & 10.3 & NA & 20.2 & NA & 29.3 \\
\hline Canada & NA & 7.4 & NA & 12.7 & NA & 22.5 \\
\hline Russia & NA & 2.7 & NA & 7.5 & NA & 29.5 \\
\hline
\end{tabular}




\begin{tabular}{l|lllcll} 
Brazil & NA & $\mathbf{3 . 6}$ & NA & $\mathbf{8 . 8}$ & NA & $\mathbf{1 6 . 0}$ \\
Mexico & NA & $\mathbf{7 . 6}$ & NA & $\mathbf{1 7 . 3}$ & NA & $\mathbf{2 7 . 2}$
\end{tabular}

All countries have a fairly low prevalence of BMI $>30 \mathrm{~kg} / \mathrm{m}^{2}$ as adulthood begins, at age 15 19 years, and the prevalence increases about threefold over the 10 years up to age 25-29 years, ultimately reaching a peak prevalence of $>20 \%$ at age $63-65$ years. The prevalence in young people is particularly high in the island states: Malta, Ireland, Iceland, New Zealand and the UK. Data taken from EUROSTAT Unit-BMI database $2014^{34}$, collected through the second wave of the European Health Interview Survey, and from the Institute for Health Metrics and Evaluation (IEHM) for $2013^{35}$. These data on the national prevalence of BMI $>30 \mathrm{~kg} / \mathrm{m}^{2}$ in young people, shown here to illustrate its progression between age groups, should not be confused with the prevalence of childhood obesity, which uses different agespecific criteria. Many children who are at risk through childhood obesity still need to gain more weight in order to reach BMI $>30 \mathrm{~kg} / \mathrm{m}^{2}$ as adults, which offers an opportunity for prevention of adult obesity at an age when weight gain is commonly most rapid. NA, not available. 
Figure 1. Initiating and sustaining a social movement. These processes were described by $\mathrm{Ganz}^{66}$, and a proposed application to movements for preventing unwanted weight gain among young people has also been included.

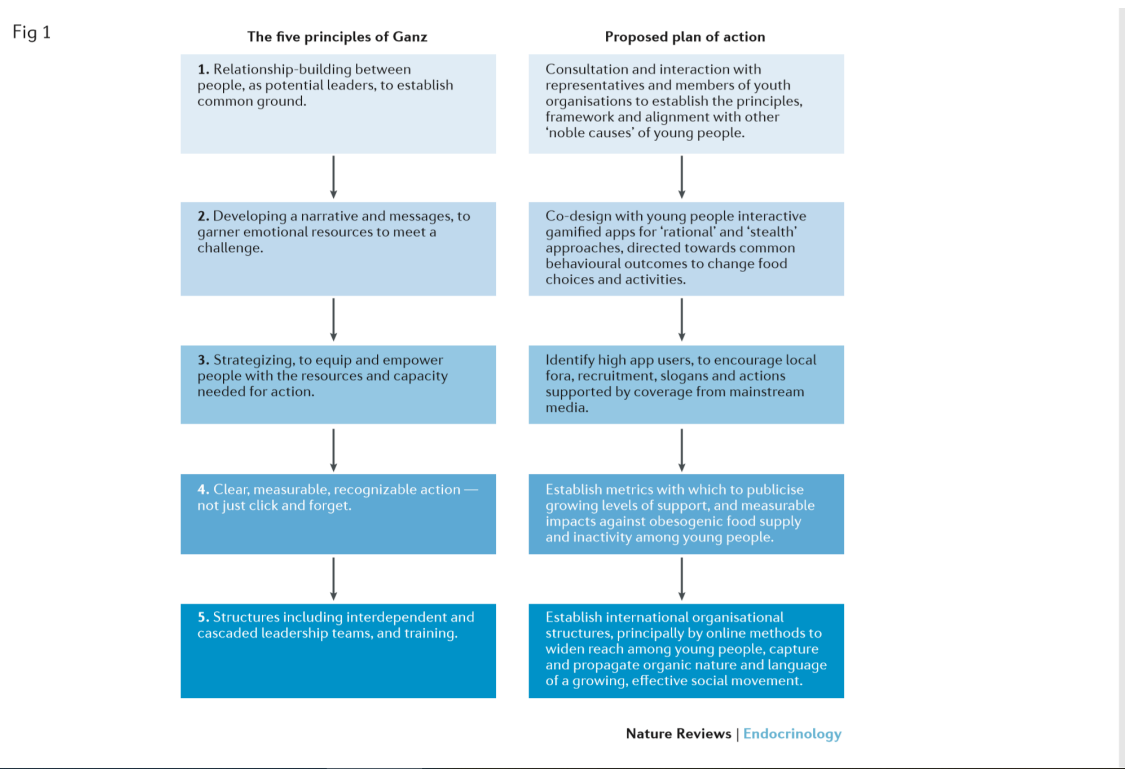

